\section{Unconscious perception: The need for a paradigm shift}

\author{
DANIEL HOLENDER \\ Université Libre de Bruxelles, Brussels, Belgium
}

and

KATIA DUSCHERER

Université de Genève, Geneva, Switzerland

According to Snodgrass, Bernat, and Shevrin (2004), unconscious perception can be demonstrated convincingly only at the objective detection threshold, provided that the conditions of their objective detection/strategic model are met, whereas both the subjective threshold model of Cheesman and Merikle (1984, 1986) and the objective threshold/rapid decay model of Greenwald, Draine, and Abrams (1996) are inconclusive. We argue on theoretical, metatheoretical, and empirical grounds that all three dual-process models, which are based on both conscious and unconscious perception, should be rejected in favor of the single-process conscious perception model.

On reading Snodgrass, Bernat, and Shevrin (2004), one has the impression that the issue of whether unconscious perception exists can be solved on methodological grounds only. Conversely, according to Merikle, Smilek, and Eastwood (2001), the methodological problems are pretty much solved, and, given that we now have incontrovertible evidence for the existence of unconscious perception, it is time to start wondering about its meaning and implications. By contrast, Marcel (1980, 1983a, 1983b) provided not only putative data but also tentative explanations of these data based on the information processing framework of the 1970s. In following his lead, Holender (1986b) not only criticized the data on methodological grounds, but also assessed the plausibility of unconscious perception in light of the available knowledge in the three situations that he examined. In the present discussion, our major reasons for rejecting the two-process models based on both unconscious and conscious perception in favor of the single-process conscious perception model are primarily theoretical and metatheoretical, but some criticisms of the recent empirical evidence will also be provided.

The first round of research on unconscious perception took place in the framework of the new look approach to

Part of this work was financed by the Belgian Fund for Joint Basic Research (FRFC, Convention 2.4562.00). Correspondence concerning this article should be addressed to D. Holender, Laboratoire de Psychologie Expérimentale, Université Libre de Bruxelles, 50 avenue F. D. Roosevelt, CP 191, B-1050 Brussels, Belgium (e-mail: holender@ulb.ac.be, katia.duscherer@pse.unige.ch).

Note-This article was accepted by the previous editorial team, headed by Neil Macmillan. perception (see Bruner, 1992), which terminated after a decade with the sweeping criticisms of Adams (1957), Eriksen (1960), and Goldiamond (1958). In assessing the early evidence for unconscious perception, Adams (1957, p. 385) pointed out that (1) alternative explanations are plausible, (2) negative results have been obtained upon replication, and (3) no replication has been reported. Pretty much the same remarks can be made about the next two rounds. A good starting point for assessing the evidence based on Stroop, Stroop-like, and semantic priming tasks gathered since Holender's (1986b) appraisal is Marcel's (1983b) theoretical account of unconscious perception.

\section{Marcel's (1983b) Account of Unconscious Perception}

Role of masking. According to Marcel (1983b), with stimuli presented at an energy level sufficient for conscious perception in the absence of masking, unconscious perception can be demonstrated only under conditions yielding predominantly central visual masking, not under conditions yielding predominantly peripheral visual masking (Michaels \& Turvey, 1979; Turvey, 1973). Optimal central masking can be achieved with dichoptic presentations (i.e., the target and the mask are presented to opposite eyes) of a target and a backward pattern mask (consisting of structural features that resemble those of the target). In central masking, the maximum reduction in target visibility occurs at positive target-mask stimulus onset asynchronies (SOAs). No or very little central masking takes place with a forward dichoptic pattern mask. Optimal peripheral masking can be achieved with monocular (or binocular) presentations of a target and either a noise mask (consisting of features that do not resemble those of the target) or a light mask (consisting of a uniformly illuminated field) in both the forward and the backward direction. ${ }^{1}$ In peripheral masking, the maximum reduction in target visibility occurs with the 0 -msec SOA. Marcel submitted that severe peripheral masking prevents sufficient processing of the sensory data to yield useful unconscious representations that can be retrieved and interpreted to form a conscious percept. By contrast, severe central masking does not affect the unconscious analysis and segmentation of the sensory information, but it blocks the access to the resulting representations, thereby interrupting the buildup of a conscious percept.

Common explanation of unconscious priming and Stroop effects. Quite expectedly at that time, Marcel (1983b) relied on Neely's (1977) two-component theory of semantic priming to account for his results on semantic priming with unconscious primes (Marcel, 1980; Marcel, 1983a, Experiment 4). Only automatic spreading activation can account for priming stemming from unconscious primes; and only facilitation from related primes, but no interference from unrelated primes, is expected, because the intentional component of priming would be completely 
disabled. With visible primes and long SOAs, only the intentional component can account for interference from unrelated primes, whereas facilitation from related primes can be due to both the intentional component and residual automatic activation (see Segui \& Beauvillain, 1987).

Less expectedly, Marcel (1983a) also attempted to rely on the spreading activation process to account for the results of his Experiment 3 based on the Stroop task with unconscious color words. His major arguments were the following: (1) By using manual instead of naming responses, one can demonstrate Stroop effects that are not due to response competition; (2) some results in the literature show that part of the Stroop interference can arise from early stages of processing; (3) verbal mediation of the unconscious Stroop effect is improbable because, contrary to what happens with verbal responses, neutral words did not slightly impair performance relative to the baseline; and (4) as noted by Marcel (1983b, p. 253), qualitatively different effects were observed with conscious and unconscious color words in one condition.

\section{Problems With Marcel's Account}

Unconscious perception and masking. If Marcel (1980, 1983a, 1983b) was right in assuming that unconscious visual perception is possible only under conditions of central masking, then, not only the earlier evidence based on stimuli presented at an energy level insufficient for conscious perception, ${ }^{2}$ but also much of the later evidence based on masking would be deemed artifactual. As regards recent research, the reason for this is that it seems more difficult to reach stringent conditions of masking in using computer screens than it was before in using tachistoscopes. One limitation is due to the refresh rates of the screens; another limitation stems from the use of the available typographical characters as masks (e.g., \&\&\&\&\&, $\% \# \% \#$, DSbuQV). Unfortunately, even with the shortest possible durations of the primes, such backward masks are not strong enough to prevent all participants from consciously identifying some of the primes or, at least, to prevent them from reconstructing some of the primes by combining conscious fragmentary information with contextual knowledge (see Kouider \& Dupoux, 2004). To remedy this situation, it is now common to sandwich the prime between a forward and a backward mask (as in Damian, 2001; Dehaene, Naccache, et al., 1998; Greenwald, Draine, \& Abrams, 1996). These manipulations, combined with the almost universal abandonment of the dichoptic viewing procedure, imply that prime degradation is predominantly due to peripheral masking processes, which according to Marcel (1980, 1983a, 1983b) should prevent unconscious perception.

Holender (1986b, Section 4.1) tried to refute Marcel's (1983b) interpretation of the role of central masking in enabling unconscious perception on the ground that even under dichoptic backward masking, central integrative processes can probably impoverish the prime as much as can the more peripheral visual interactions. Bridgeman (1986) criticized this interpretation based on Breitmeyer and Ganz's (1976) psychophysiological theory of masking, but neither he nor Breitmeyer (1984; Breitmeyer \& Ogmen, 2000) ever stated anything about the plausibility of Marcel's interpretation of masking. This is unfortunate, because if Marcel was wrong in explaining unconscious perception by the disruption in the retrieval of intact unconscious records of early visual processes, we would lose any rational argument for believing that unconscious perception at an objective threshold is at all a plausible phenomenon. We would also be licensed to degrade the stimulus by any means, which is pretty much what most researchers do, anyway.

Priming effects versus congruency effects. Overall, Marcel's (1983b) attempt to use Neely's (1977) theory of priming to justify unconscious perception was not very successful. One anomaly is that with a 2,000-msec primetarget SOA, the semantic priming effect should have been larger, instead of equal, with conscious than with unconscious primes in Experiment 4 of Marcel (1983a). Another problem is that, as was noted by Paap (1986), there is a contradiction between the facilitation unaccompanied by interference generated by unconscious ambiguous words (Marcel, 1980) and the facilitation accompanied by interference generated by unconscious color words in Experiment 3 of Marcel (1983a). Paap wondered if "strong Stroop interference will occur only with conscious identification" (p. 46). Indeed, it does, as will be argued below.

It is important to maintain a distinction between priming effects and congruency effects (Holender, 1992; Holender \& Duscherer, 2002). Much of the early evidence for unconscious semantic access under masking was based on a semantic priming paradigm yielding what was taken as bona fide semantic priming effects. ${ }^{3}$ The prototypical case was Experiment 4 of Marcel (1983a). Much of the recent evidence is based on Stroop and Stroop-like tasks yielding congruency effects, not priming effects. Congruency effects arise from the fact that the distractors have the power to activate the responses from the response repertory of the task. In congruent trials, the distractor activates the same response as does the relevant information; it activates a different response in incongruent trials (see Holender, 1992; Kornblum, 1992; Kornblum, Hasbroucq, \& Osman, 1990; Kornblum \& Lee, 1995). This logical analysis is corroborated by the use of the lateralized readiness potential, which is assumed to be a reasonable index of central activation associated with left and right limb responses (e.g., De Jong, Liang, \& Lauber, 1994; Eimer, 1998; Miller \& Navon, 2002). Thus, Stroop and Strooplike effects based on manual responses are due to response conflicts, not to spreading activation in a semantic network as in Marcel's (1983a, 1983b) interpretation of the Stroop effect with manual responses.

\section{Assessment of the Dual-Process Models}

The subjective threshold model. The various research strategies developed by Merikle and associates that Snodgrass et al. (2004) subsume under the subjective threshold model address fundamental issues. One such issue is 
whether it is possible to demonstrate unconscious perception in a way that does not eliminate phenomenal awareness from the definition of conscious perception. Merikle and Cheesman (1986, 1987; Cheesman \& Merikle, 1984, 1986) attempted to solve this problem by moving the boundary between conscious and unconscious perception at a subjective threshold and by corroborating this approach by finding qualitatively different effects below and above this boundary. All their early work was based on the classical Stroop task with naming responses, and masking was dichoptic. The results showed that (1) there was no Stroop effect at the objective identification threshold (i.e., chance performance for a forced choice between two or four color words; see also Tzelgov, Porat, \& Henik, 1997); (2) there was a monotonic increase in the Stroop effect between the objective identification threshold and a clearly suprathreshold SOA; (3) there was a significant Stroop effect at the subjective identification threshold (i.e., the SOA for which participants judged their forced-choice performance to be at chance), which corresponded to an SOA substantially longer than the one corresponding to the objective identification threshold; and (4) qualitatively different effects - a normal Stroop effect with unconscious words versus a reversed Stroop effect (i.e., faster responses with incongruent than with congruent trials) with readable words - were found in a two-color variant of the task, in which the proportion of trials was strongly biased in favor of incongruent trials, thereby favoring intentional strategies based on expectancies, provided that the color words were suprathreshold. The first three points correspond to the situation illustrated in Figure 3C in Snodgrass et al.

In more recent work with the Stroop task done by Merikle, Joordens, and Stolz (1995; Merikle \& Joordens, 1997), the dichoptic masking procedure was abandoned and no threshold was measured. The absence of reversal in the Stroop effect in spite of the high proportion of incongruent trials was interpreted as evidence for unconscious perception. This occurred (1) for the SOAs yielding maximum exclusion failures in a stem completion task in Experiment 2 of Merikle et al. (1995), (2) when the color words were masked after a constant 33-msec SOA in Experiment 1A of Merikle and Joordens (1997; see also Daza, Ortells, \& Fox, 2002), and (3) when the color words were presented for $300 \mathrm{msec}$ but participants had to perform a difficult secondary task in the divided attention condition of Experiment 1B of Merikle and Joordens.

Holender (1986a, 1986b, 1987) raised three major objections against the early work of Merikle and associates, which also apply to their more recent work. The first objection is that the discrepancy between the objective and the subjective identification thresholds in Cheesman and Merikle $(1984,1986)$ was probably due to the fact that the former was estimated on a trial-by-trial basis, whereas the latter was estimated on the basis of retrospective evaluative judgments taking place after each block of trials. This objection is now supported by the results of Experiment 2 of Kunimoto, Miller, and Pashler (2001), which show that when the two thresholds are measured on a trial-by-trial basis, the SOA corresponding to the subjective identification threshold is only 4 msec longer than the SOA corresponding to the objective identification threshold. This is probably too small a difference between SOAs to expect quantitative or qualitative differences to appear in indirect measures of perception such as the Stroop effect.

The second objection is that qualitatively different effects can be observed with conscious stimuli. Therefore, in the absence of independent assessments of participants' conscious perception of the prime color words, the absence of reversal in the Stroop effects found in Experiment 2 of Merikle et al. (1995) and in Experiments 1A and 1B of Merikle and Joordens (1997) hardly constitutes evidence for unconscious perception. Similar criticisms have also been raised by Haase and Fisk (2001) and by Snodgrass (2002) against the interpretation of the exclusion task used in Experiment 1 of Merikle et al. (1995), and by Klinger (2001) against the interpretation of the illusion of memory (Jacoby \& Whitehouse, 1989) used in Experiment 3 of Merikle et al. (1995).

The third objection, also clearly stated by Lupker (1986), is that between the objective identification threshold and suprathreshold presentation conditions there is a continuum of increasing knowledge based on fragmentary conscious information (i.e., letter features, letters, global shape) that can be combined with contextual information to make an informed guess about the identity of the masked word. The way partial consciousness works in Experiment 1A of Merikle and Joordens (1997) has been nicely illustrated by the study of Kouider and Dupoux (2004).

Taken together, the research on the Stroop task has never confirmed the results of Experiment 3 of Marcel (1983a). There is no Stroop effect at the objective identification threshold defined in terms of chance performance for forced-choice discrimination between the color words. Moreover, the finding of a satisfactory boundary between conscious and unconscious perception above the objective threshold is marred by inextricable problems. It is clear from their treatment of the subjective threshold model that Snodgrass et al. (2004) fully endorse these conclusions. Yet, unlike us, they would not consider the issue to be completely settled until the Stroop effect has been studied at the objective detection threshold (i.e., chance performance in a presence/absence judgment) as well.

The objective threshold/rapid decay model. From their summary statements about what they call the objective threshold/rapid decay model, it seems that Snodgrass et al. (2004) endorse the major criticisms that have been raised against Greenwald and associates' work (Draine \& Greenwald, 1998; Greenwald et al., 1996; Greenwald, Klinger, \& Schuh, 1995), including those concerned with the regression approach to the null sensitivity problem. Yet at various places Snodgrass et al. (2004) rely on some of this work to make their point (see next subsection). We think this model doubly misnamed, because it is question- 
able that an objective threshold has ever been reached by using the regression approach, and it is doubtful that the rapid decay course of the effect has any generality.

With respect to the objective threshold problem, none of the criticisms raised against the regression method (Dosher, 1998; Merikle \& Reingold, 1998; Miller, 2000) can be overlooked, since none of them has been adequately rebutted thus far. Three rather straightforward remarks will dispense us to enter into the detail of these criticisms. First, the logic of the dissociation paradigm implies that each individual participant should be at chance for a relevant index of conscious perception; only very slight deviations from null sensitivity could be tolerated. However, the examination of the published regression graphs shows that very few participants satisfy this criterion. Second, if $d^{\prime}$ has a theoretical lower bound of zero, only a few participants should have small negative values of $d^{\prime}$ due to measurement errors. This is not always so. For example, Figure 4 of Snodgrass et al. (2004), which reproduces the lower panel of Figure 4 of Greenwald et al. (1995), summarizes the results of 1,431 participants, of whom about one third have negative values of $d^{\prime}$ ranging from -1.0 to 0 (see the upper panel of Figure 4 in Greenwald et al., 1995). Moreover, sometimes about as many participants have negative than positive values of $d^{\prime}$, as is the case in Figures 5 and 6 of Snodgrass et al. (2004), in which the values of $d^{\prime}$ range from about -1.0 to $+1.0 .{ }^{4}$ Third, it is questionable that reliable regression results could be obtained if the method were used with data sets of "realistic size" (see Klauer \& Greenwald, 2000, p. 1507 for references) ranging from as few as 12 or 15 participants to at most 50 or 60 participants.

We now examine the rapid decay claim, which, like most of the work carried out by Greenwald and associates since the initial study of Greenwald, Klinger, and Liu (1989), rests on the use of the so-called affective priming paradigm of Fazio, Sanbonmatsu, Powell, and Kardes (1986). In this paradigm, both the prime and the target are polarized words that have strong positive and negative affective connotations. In making binary responses according to whether the target has a positive or a negative connotation, participants are faster in congruent trials, in which both the prime and the target have the same polarity, than in incongruent trials, in which they have opposite polarities. It took surprisingly long to realize that although this effect is mediated by the affective meaning of the words, it is caused by response synergy and response competition due to prime-target congruency, not by spreading activation in a semantic network. This issue is now completely settled in both the studies resting on clearly visible primes (e.g., De Houwer, Hermans, Rothermund, \& Wentura, 2002; Klauer, 1998; and references therein) and in the studies resting on near threshold primes (Klinger, Burton, $\&$ Pitts, 2000). The crucial point is that even with visible primes, the congruency effect observed with affectively polarized words is short lived; it is generally observed only with SOAs shorter than $300 \mathrm{msec}$ (e.g., Klauer, 1998).

Consequently, it is because they mistook a congruity effect for a semantic priming effect that Draine and Green- wald (1998) claim that semantic priming with near threshold primes is short lived. However, genuine semantic priming effects based on near threshold primes used in the standard semantic priming paradigm were obtained with a 2,000-msec SOA (Marcel, 1983a, Experiment 4), and it was larger with this SOA than with short ones of $200 \mathrm{msec}$ (Fowler, Wolford, Slade, \& Tassinary, 1981, Experiment 6) or $350 \mathrm{msec}$ (Balota, 1983). Hence, there is no generality to the claim that putatively unconscious effects mediated by the meaning of stimuli are necessarily very short lived; it all depends on which paradigm is used.

Let us return to the mistaken interpretation of the affective priming effect in terms of spreading activation. It should be pointed out that although the identity and the denotative meaning of a stimulus can be considered as stored retrievable knowledge, the numerous connotations that can be associated with any stimulus do not correspond to stored semantic knowledge, but can be generated on the basis of stored knowledge. Thus, neither the affective connotation of the prime words (see Duscherer, Holender, \& Molenaar, 2004) nor the fact that a number is smaller or larger than five (Dehaene, Naccache, et al., 1998; Naccache \& Dehaene, 2001) can affect target processing through spreading activation, but they can generate congruency effects in binary decisions on these targets. It is hard to understand how such effects could be mediated unconsciously. Therefore, one must be very suspicious about the stringency of threshold determination whenever such effects are found.

To sum up, (1) it is questionable that an "objective threshold" has ever been reached by using the regression approach, (2) there is no generality to the "rapid decay" course of the affective priming effect, and (3) semantic effects based on the connotation (instead of the denotation) of stimuli can hardly be explained by spreading activation.

The objective threshold/strategic model. Dissatisfied with the inconclusive results yielded by the two dualprocess models just assessed, Snodgrass et al. (2004) propose to remedy the situation by looking at nonmonotonic relations between the indirect and the direct indexes of perception. The major assumptions underlying their $o b$ jective threshold/strategic model are that (1) "conscious perception functions on a hierarchical strength/complexity continuum, such that greater stimulus intensity is required in order for more complex effects to occur"; (2) "direct measures that index fundamental, lower level stimulus features are exhaustively sensitive with respect to effects that require higher level processing"; and (3) "effects that violate the strength/complexity continuum provide strong evidence for unconscious perception, whereas effects consistent with this continuum do not" (p. 849). Three further assumptions are needed for an observed nonmonotonic relationship to unambiguously demonstrate unconscious perception: (4) "Conscious and unconscious perceptual influences are functionally exclusive"; (5) "the former override the latter when ... participants regard their conscious perception as relevant given the task context" (p. 855); and (6) "it is clear that conscious percep- 
tion would produce monotonically increasing positive effects" (p. 857). Figure 3A in Snodgrass et al. (2004) illustrates the sought for empirical relation. The indirect index of perception must be positive at the objective detection threshold; it must then decrease to reach a zero value at the objective identification threshold; beyond the objective identification threshold, the indirect index of perception should increase monotonically as a function of increasing availability to consciousness of the task-relevant aspect of the stimulus.

With respect to Assumptions 1 and 2, Snodgrass et al. (2004) argue that detection is exhaustively sensitive relative to identification, which itself is exhaustively sensitive relative to processing based on the meaning of the stimuli, such as that required by semantic classification tasks. They further argue that when effects based on spreading activation are concerned, it is preferable to measure the identification threshold rather than a threshold based on the semantic classification task itself. However, as we saw in the preceding subsection, it is a mistake to attribute effects observed in binary semantic classification to spreading activation; these are congruency effects, not semantic priming effects. We also questioned the fact that objective thresholds could be reached by using the regression method, which implies that Draine and Greenwald's (1998, Experiment 4) and Klinger et al.'s (2000) experiments hardly constitute evidence that the lexical decision is a more sensitive direct index than semantic classification at the objective threshold.

This being said, Snodgrass and associates would probably easily accept that in our work on the number classification task of Dehaene, Naccache, et al. (1998), we measured the objective threshold SOAs for the smaller/larger than five classification of the masked prime number, instead of for prime number identification (Holender \& Duscherer, 2003). Our results parallel those of Cheesman and Merikle (1984) with the Stroop task: The congruency effect was null at the objective classification threshold, and it increased monotonically with increasing values of $d^{\prime}$. We consider this evidence sufficient to demonstrate that Dehaene, Naccache, et al.'s apparent unconscious effect was due to the extreme leniency and inadequacy of their threshold establishment procedure. However, Snodgrass et al. (2004) would not accept this conclusion before we also show that there is no congruency effect at the objective detection threshold, thus implementing the overall pattern of results idealized in their Figure 3B, instead of that of their Figure 3A. Of course, this requirement demands that the objective detection threshold be substantially lower than the objective identification threshold. Snodgrass et al. (2004) adduce some empirical evidence that this is the case in some experimental settings, in which a prime field is followed by a backward mask. ${ }^{5}$ However, there is no reason to expect that this requirement will be satisfied whatever the parameters of the situation, as Duncan (1985) pointed out. ${ }^{6}$

Let us now briefly examine what Snodgrass et al. (2004) consider to be reliable evidence for unconscious percep- tion occurring at the objective detection threshold, found in 20 experiments, 7 of which also show the "negative and/or nonmonotonic relationships." Overall, these studies are assumed to have provided "stronger and more consistent evidence for ODT" than did earlier studies criticized by Holender (1986a, 1986b, 1987) and others; and those showing the nonmonotonic relationship are assumed to have satisfied Assumptions 4, 5, and 6. We are less optimistic than Snodgrass et al. about much of this evidence. If replicable under stringent conditions of threshold determination, the studies of Dagenbach, Carr, and Wilhelmsen (1989; Carr \& Dagenbach, 1990), Groeger (1988), and Klinger and Greenwald (1995) offer the best available support.

As for the rest of the evidence based on the dissociation paradigm, we have seen in the preceding subsection that we doubt that Greenwald et al.'s (1989) affective congruity effect can be obtained with completely unconscious primes. We have also criticized the evidence stemming from the regression analysis of the position discrimination task of Greenwald et al. (1995) in note 4. Finally, in the next section, we shall offer an alternative interpretation of Snodgrass and associates' studies based on double direct measures of consciousness (Snodgrass \& Shevrin, 2002; Snodgrass, Shevrin, \& Kopka, 1993; Van Selst \& Merikle, 1993).

To conclude this assessment of Snodgrass et al.'s (2004) proposal, we see little empirical evidence for the objective threshold/strategic model. Yet, we think that on methodological grounds, this proposal is far superior to the subjective threshold and to the objective threshold/rapid decay models. Its two major assets are that it requires the establishment of several objective thresholds and thereby demands that studies be comprehensive enough to remove many of the ambiguities from the existing literature. All one has to do is to set up a comprehensive study in which one determines both an objective detection and an objective identification/classification threshold. One must also add a clearly suprathreshold condition, in order to know how big the indirect index of perception can get. Of course, one must choose the best possible threshold hunting method (see Kunimoto et al., 2001) and, we are afraid, one must establish each threshold twice, once in the absence of the targets and once in their presence, because each method has its advantages and disadvantages (e.g., Dark, 1988; Dark \& Benson, 1991; Merikle \& Reingold, 1990; Reingold \& Merikle, 1988).

\section{In Defense of the Single-Process Conscious Perception Model}

Alternative explanations. At the time of Adams's (1957) assessment of the first round of research on unconscious perception, the only effect that was reliably established was the discrepancy between participants' above chance performance in forced-choice discrimination and their total lack of confidence in their judgments in simple psychophysical tasks. Adams noted that there had been no attempt to manipulate the discrepancy between confidence judgments and performance. We are now in a bet- 
ter position, because Kunimoto et al. (2001, Experiment 1) and Haase and Fisk (2001, Experiment 1) have shown that confidence predicts accuracy in forced-choice identification judgments. Kunimoto et al. (Experiments 2-4) have also shown that the difference in favor of the objective threshold over the subjective threshold becomes very small (2-4 msec) when participants discriminate among stimuli and indicate their confidence on each trial, provided that both thresholds are measured in a way that eliminates decisional biases.

Another important discrepancy is that between exclusion failure and exclusion success in the exclusion task used either alone (Merikle \& Joordens, 1997; Merikle et al., 1995) or in conjunction with the inclusion task (Debner \& Jacoby, 1994; Visser \& Merikle, 1999). Visser and Merikle's finding that incentives increase participants' performance in the exclusion task but not in the inclusion task seriously undermines the interpretation of the discrepancy as evidence for unconscious perception, especially because Snodgrass (2002; see also Haase \& Fisk, 2001, Experiment 2 ) is probably right in interpreting exclusion failure as a criterion artifact in a signal detection theory (SDT) framework. Given that working under the exclusion instruction is difficult (see Block, 2001), we think that it is not sufficient to simply ask participants to complete the stems according to each instruction, but that they should also be asked to rate their confidence in their response on each trial. It may well be the case that the difference in completion performance would not subsist at equal levels of confidence ratings under the inclusion and exclusion instructions.

Adams (1957) also pointed out that alternative explanations of the replicable effects are possible. One important source of alternative interpretation is SDT (Goldiamond, 1958). Macmillan (1986) clearly stated how the subliminal perception issue should be translated into SDT concepts. If, instead of using the $d^{\prime}=0$ detection criterion, one uses what Macmillan called an empirical threshold, which corresponds to participants' subjective placing of a criterion at some positive value of $d^{\prime}$ below and above which they make negative and positive detection responses, respectively, then, finding above chance recognition/ identification below this criterion would not constitute evidence for unconscious perception. Similarly, Björkman, Juslin, and Winman (1993) refuse to interpret the discrepancy between participants' underconfidence in their performance and their actual forced-choice performance in psychophysical tasks as evidence for unconscious perception. In providing a theoretical framework for how decisions are made under uncertainty in experimental and practical diagnostic tasks (see Swets, 1996), SDT almost naturally predicts that some performance discrepancy could occur under slightly different task instructions. If so, what is usually called implicit or unconscious perception does not refer to a separate state of the processing system but simply denotes perception under high uncertainty.

The single-process conscious perception model is sufficient to explain replicable effects that are puzzling at first sight. One example is that there is no need to postulate a center-surround attentional process taking place in semantic memory to account for the reversal in the semantic priming effect (faster responses in unrelated than in related trials) when participants make a semantic similarity judgment on masked primes in a preliminary task (Carr \& Dagenbach, 1990; Dagenbach et al.,1989). Kahan (2000) accounts for this effect by a retrospective prime clarification process stemming from participants' deliberate attempt to extract the meaning of the masked word, with this strategy itself being promoted by the preliminary task. Another example is that it is not necessary to postulate a powerful unconscious that can make affective preference judgments on stimuli that cannot be recognized (Zajonc, 1980). This effect can simply result from applying a more effective nonanalytic strategy in preference judgments, and a less effective analytic strategy in recognition judgments (Whittlesea \& Price, 2001). This alternative interpretation can be readily applied to the data of Snodgrass and Shevrin (2002; see also Snodgrass et al., 1993; Van Selst \& Merikle, 1993) showing an interaction between participants" preference for the "pop" nonanalytic strategy or the "look" analytic strategy and the actual strategy they had to use. This interaction showed that performance was below chance in the nonpreferred strategy and above chance in the preferred one, even though overall performance was at chance. Finally, our own work supports the idea that congruency effects are caused by conflicts and synergies between conscious mental contents (Duscherer et al., 2004; Holender, 1992; Holender \& Duscherer, 2003), and that such is also the case for negative semantic priming effects (Duscherer \& Holender, 2002, 2003).

The need for a paradigm shift. There is a major change in the metatheoretical framework underlying our present discussion relative to the framework adopted by the first author in his previous appraisal of unconscious perception. Holender (1986a, 1986b, 1987) was not questioning the conventional information processing framework used by Marcel (1983b) for rationalizing unconscious perception, nor the similar formulation of Fodor $(1983,1985)$ in his functional taxonomy of cognitive mechanisms. Thus, although the possible existence of unconscious, modular semantic processing was not questioned, there were doubts about whether the result of such processing, referred to as "semantic activation," would not generate conscious mental contents involving the identity and the meaning of the stimulus, referred to as "conscious identification." There were also doubts about whether the usual priming and Stroop-like tasks really tap into the modular input systems, instead of into nonmodular decisional processes (Holender, 1990, 1992).

The choice of the terms activation and identification was not optimal, because activation is too laden theoretically. A more descriptive term such as access would probably have been preferable. Paap (1986) criticized Holender's (1986b) imprecise use of the term identification, which sometimes even implied discrimination. This being 
granted, the main purpose of the formulation opposing semantic activation to conscious identification was to avoid making a contrast between "unconscious" and "conscious" perception in terms of mental content, not in terms of mental processes. This reluctance to attribute perceptual contents to the processing system is now reinforced by our adoption of a metatheoretical framework inspired by Searle's $(1990,1992)$ criticisms of cognitive science. In this framework, a percept is a conscious mental content that a person has, not an unconscious mental representation.

The problem we are facing is that neither the functional distinction between modular and central cognitive mechanisms proposed by Fodor $(1983,1985)$ nor the more fleshed out version proposed by Dehaene, Kerszberg, and Changeux (1998; Dehaene \& Naccache, 2001) has much to say about consciousness, intentionality, or meaning. Similarly, in evaluating the relative merits of two major computational approaches to cognition-connectionism and ACT-R - on 12 criteria, Anderson and Lebiere (2003) almost completely eschew these problems. Of course, the point is not to blame anybody for the current state of our knowledge about the relation between the brain and the mind. However, the interest of Searle's $(1990,1992)$ approach to cognitive science is that it rests on a logical analysis of the relation between intentionality and consciousness (Searle, 1983) that is lacking elsewhere. There is no room to develop this point of view here; suffice it to say that it implies that the single-process conscious perception model is sufficient to explain all the cognitive phenomena. Of course, it is possible to come to the same conclusion from different directions, as is evident from the fact that an increasing number of researchers are actually defending similar points of view without endorsing or even mentioning Searle's stance (e.g., Dulany, 1997; Perruchet \& Vinter, 2002; Uttal, 1998, 2000, 2001).

\section{Concluding Comments}

In our evaluation of Snodgrass et al.'s (2004) proposal and in our rejection of the dual-process models in general, we have been dealing only with priming tasks based on the meaning of the unconscious primes and with Stroop and Stroop-like tasks based on the identity and the meaning of the unconscious distractors, which elicit congruency effects. This has enabled us to discuss most of the evidence for unconscious perception quoted by Snodgrass et al. There are other examples of congruency effects, which are based on physical attributes of a limited set of only two stimuli, that we have not discussed here, because we believe that they require a treatment separate from that of the studies based on the denotative and connotative meanings of the stimuli. Some of this work is based on metacontrast masking (e.g., Ansorge, Klotz, \& Neumann, 1998; Jaskowski, Van der Lubbe, Schlotterbeck, \& Verleger, 2002; Klotz \& Neumann, 1999; Klotz \& Wolff, 1995; Leuthold \& Kopp, 1998; Neumann \& Klotz, 1994; Vorberg, Mattler, Heinecke, Schmidt, \& Schwarzbach, 2003); other work is based on backward masking (e.g., Eimer \& Schlaghecken, 1998, 2001, 2002; Klapp \& Hinkley, 2002; Schlaghecken \& Eimer, 1997, 2002).
The neuropsychological evidence should also be analyzed separately. In the meantime, one should be cautious about unwarranted generalizations. For example, Jack and Shallice (2001, p. 163) found it "unlikely that there will be yet another collapse of confidence in the hypothesis of perception without awareness, in part because of the influential contribution of neuropsychological evidence." Note, however, that in their analysis of unilateral neglect and extinction, Driver and Vuilleumier (2001) contrast this deficit due to lesions in the right parietal lobe, while the primary sensory areas are intact, with blindsight, in which the primary sensory areas are damaged. If we were pretending that after a second lesion damaging the primary sensory areas, a patient already suffering from unilateral neglect would still present the typical pattern of extinction he/she had before, either the neuropsychological community would not believe us, or it would provide an anatomical explanation in terms of preserved pathways. We are waiting for an alternative explanation of unconscious perception under severe masking once Marcel's (1983b) explanation based on the distinction between peripheral and central masking is lost.

\section{REFERENCES}

ADAMS, J. K. (1957). Laboratory studies of behavior without awareness. Psychological Bulletin, 54, 383-405.

ANDERSON, J. R., \& LEBIERE, C. (2003). The Newell test for a theory of cognition. Behavioral \& Brain Sciences, 26, 587-640.

Ansorge, U., Klotz, W., \& NeumanN, O. (1998). Manual and verbal responses to completely masked (unreportable) stimuli: Exploring some conditions for the metacontrast dissociation. Perception, 27, 1177-1189.

BALOTA, D. A. (1983). Automatic semantic activation and episodic memory encoding. Journal of Verbal Learning \& Verbal Behavior, 22, 88-104.

BJÖRKMAN, M., JusLin, P., \& WinMan, A. (1993). Realism of confidence in sensory discrimination: The underconfidence phenomenon. Perception \& Psychophysics, 54, 75-81.

BLOCK, N. (2001). Paradox and cross purposes in recent work on consciousness. Cognition, 79, 197-219.

Breitmeyer, B. G. (1984). Visual masking: An integrative approach. New York: Oxford University Press.

Breitmeyer, B. G., \& Ganz, L. (1976). Implications of sustained and transient channels for theories of visual pattern masking, saccadic suppression, and information processing. Psychological Review, 83, 1-36.

Breitmeyer, B. G., \& OGMEN, H. (2000). Recent models and findings in visual backward masking: A comparison, review, and update. Perception \& Psychophysics, 62, 1572-1595.

BRIDGEMAN, B. (1986). Theories of visual masking. Behavioral \& Brain Sciences, 9, 25-26.

Bruner, J. (1992). Another look at New Look 1. American Psychologist, 47, 780-783.

CARR, T. H., \& DAGENBACH, D. (1990). Semantic priming and repetition priming from masked words: Evidence for a center-surround attentional mechanism in perceptual recognition. Journal of Experimental Psychology: Learning, Memory, \& Cognition, 16, 341-350.

Cheesman, J., \& Merikle, P. M. (1984). Priming with and without awareness. Perception \& Psychophysics, 36, 387-395.

Cheesman, J., \& MerikLe, P. M. (1986). Distinguishing conscious from unconscious perceptual processes. Canadian Journal of Psychology, 40, 343-367.

DaGenbaCh, D., CARr, T. H., \& Wilhelmsen, A. (1989). Task-induced strategies and near-threshold priming: Conscious influences on unconscious perception. Journal of Memory \& Language, 28, 412-443.

Damian, M. F. (2001). Congruity effects evoked by subliminally presented primes: Automaticity rather than semantic processing. Journal 
of Experimental Psychology: Human Perception \& Performance, 27, 154-165.

DARK, V. J. (1988). Semantic priming, prime reportability, and retroactive priming are interdependent. Memory \& Cognition, 16, 299-308.

DARK, V. J., \& BENSON, K. (1991). Semantic priming and identification of near threshold primes in a lexical decision task. Quarterly Journal of Experimental Psychology, 43A, 53-78.

DaZA, M. T., Ortells, J. J., \& Fox, E. (2002). Perception without awareness: Further evidence from a Stroop priming task. Perception \& Psychophysics, 64, 1316-1324.

DEBNER, J. A., \& JACOBY, L. L. (1994). Unconscious perception: Attention, awareness, and control. Journal of Experimental Psychology: Learning, Memory, \& Cognition, 20, 304-317.

Dehaene, S., Kerszberg, M., \& CHANGeUX, J.-P. (1998). A neuronal model of a global workspace in effortful cognitive tasks. Proceedings of the National Academy of Sciences, 95, 14529-14534.

DeHAENE, S., \& NaCCACHE, L. (2001). Towards a cognitive neuroscience of consciousness: Basic evidence and a workspace framework. Cognition, 79, 1-37.

Dehaene, S., NACCACHE, L., Le Clec'H, G., Koechlin, E., Mueller, M., Dehaene-Lambertz, G., van de Moortele, P.-F., \& Le Bihan, D. (1998). Imaging unconscious semantic priming. Nature, 395, 597600.

De Houwer, J., Hermans, D., Rothermund, K., \& Wentura, D. (2002). Affective priming of semantic categorisation responses. $\mathrm{Cog}_{\text {- }}$ nition \& Emotion, 16, 643-666.

De Jong, R., Liang, C.-C., \& LAuber, E. (1994). Conditional and unconditional automaticity: A dual-process model of effects of spatial stimulus-response correspondence. Journal of Experimental Psychology: Human Perception \& Performance, 20, 731-750.

Dosher, B. A. (1998). The response-window regression method-Some problematic assumptions: Comment on Draine and Greenwald (1998). Journal of Experimental Psychology: General, 127, 311-317.

Draine, S. C., \& GreENWALD, A. G. (1998). Replicable unconscious semantic priming. Journal of Experimental Psychology: General, 127, 286-303.

Driver, J., \& Vuilleumier, P. (2001). Perceptual awareness and its loss in unilateral neglect and extinction. Cognition, 79, 39-88.

Dulany, D. E. (1997). Consciousness in the explicit (deliberative) and implicit (evocative). In J. D. Cohen \& J. W. Schooler (Eds.), Scientific approaches to consciousness (pp. 179-212). Mahwah, NJ: Erlbaum.

DunCAN, J. (1985). Two techniques for investigating perception without awareness. Perception \& Psychophysics, 38, 296-298.

Duscherer, K., \& Holender, D. (2002). No negative semantic priming from unconscious flanker words in sight. Journal of Experimental Psychology: Human Perception \& Performance, 28, 839-853.

Duscherer, K., \& Holender, D. (2003). Semantic priming from flanker words: Some limitation to automaticity. Psychologica Belgica, 43, 153-179.

Duscherer, K., Holender, D., \& MolenaAr, E. (2004). Revisiting the affective Simon effect. Manuscript submitted for publication.

EIMER, M. (1998). The lateralized readiness potential as an on-line measure of central response activation processes. Behavior Research Methods, Instruments, \& Computers, 30, 146-156.

EIMER, M., \& SCHLAGHECKEN, F. (1998). Effects of masked stimuli on motor activation: Behavioral and electrophysiological evidence. Journal of Experimental Psychology: Human Perception \& Performance, 24, 1737-1747.

EIMER, M., \& SCHLAGHECKEN, F. (2001). Response facilitation and inhibition in manual, vocal, and oculomotor performance: Evidence for a modality-unspecific mechanism. Journal of Motor Behavior, 33, 16-26.

Eimer, M., \& Schlaghecken, F. (2002). Links between conscious awareness and response inhibition: Evidence from masked priming. Psychonomic Bulletin \& Review, 9, 514-520.

ERIKSEN, C. W. (1960). Discrimination and learning without awareness: A methodological survey and evaluation. Psychological Review, 67, 279-300.

FazIo, R. H., Sanbonmatsu, D. M., Powell, M., \& Kardes, F. R. (1986). On the automatic activation of attitudes. Journal of Personality \& Social Psychology, 50, 229-238.
FoDOR, J. A. (1983). The modularity of mind. An essay on faculty psychology. Cambridge, MA: MIT Press.

Fodor, J. A. (1985). Précis of The Modularity of Mind. Behavioral \& Brain Sciences, 8, 1-42.

Fowler, C., Wolford, G., Slade, R., \& Tassinary, L. (1981). Lexical access with and without awareness. Journal of Experimental Psychology: General, 110, 341-362.

GoLDIAMOND, I. (1958). Indicators of perception: I. Subliminal perception, subception, unconscious perception: An analysis in terms of psychophysical indicator methodology. Psychological Bulletin, 55, 373-411.

Greenwald, A. G., Draine, S. C., \& Abrams, R. L. (1996). Three cognitive markers of unconscious semantic activation. Science, $\mathbf{2 7 3}$, 1699-1702.

GREENWALD, A. G., Klinger, M. R., \& LiU, T. J. (1989). Unconscious processing of dichoptically masked words. Memory \& Cognition, 17 , 35-47.

GREenwald, A. G., Klinger, M. R., \& Schuh, E. S. (1995). Activation by marginally perceptible ("subliminal") stimuli: Dissociation of unconscious from conscious cognition. Journal of Experimental Psychology: General, 124, 22-42.

GROEGER, J. (1988). Qualitatively different effects of undetected and unidentified auditory primes. Quarterly Journal of Experimental Psychology, 40A, 323-339.

HAASE, S. J., \& FISK, G. D. (2001). Confidence in word detection predicts word identification: Implications for an unconscious perception paradigm. American Journal of Psychology, 114, 439-468.

HAASE, S. J., \& FisK, G. D. (2004). Valid distinctions between conscious and unconscious perception? Perception \& Psychophysics, 66, 868871.

Holender, D. (1986a). Conceptual, experimental, and theoretical indeterminacies in research on semantic activation without conscious identification. Behavioral \& Brain Sciences, 9, 50-66.

HolENDER, D. (1986b). Semantic activation without conscious identification in dichotic listening, parafoveal vision, and visual masking: A survey and appraisal. Behavioral \& Brain Sciences, 9, 1-23.

HolENDER, D. (1987). Semantic activation without conscious identification: Can progress be made? Behavioral \& Brain Sciences, 10, 768-773.

Holender, D. (1990). On doing research on consciousness without being aware of it. Behavioral \& Brain Sciences, 13, 612-614.

HolENDER, D. (1992). Expectancy effects, congruity effects, and the interpretation of response latency measurement. In J. Alegria, D. Holender, J. Junca de Morais, \& M. Radeau (Eds.), Analytic approaches to human cognition (pp. 351-375). Amsterdam: North-Holland.

Holender, D., \& Duscherer, K. (2002). Unconscious semantic access: A case against an hyperpowerful unconscious. Behavioral \& Brain Sciences, 25, 340-341.

Holender, D., \& Duscherer, K. (2003). “Unconscious" semantic congruency effects depend on prime discriminability. Abstracts of the Psychonomic Society, 8, 135.

JACK, A. I., \& SHALliCE, T. (2001). Introspective physicalism as an approach to the science of consciousness. Cognition, 79, 161-196.

JACOBY, L. L., \& Whitehouse, K. (1989). An illusion of memory: False recognition influenced by unconscious perception. Journal of Experimental Psychology: General, 118, 126-135.

JaSKowsKi, P., VAN DER Lubbe, R. H. J., SChLotTerbeck, E., \& VerLEGER, R. (2002). Trace left on visual selective attention by stimuli that are not consciously identified. Psychological Science, 13, 48-54.

KaHAN, T. A. (2000). Negative priming from masked words: Retrospective prime clarification or center-surround inhibition? Journal of Experimental Psychology: Learning, Memory, \& Cognition, 26, 13921410.

KLAPP, S. T., \& HinkLEy, L. B. (2002). The negative compatibility effect: Unconscious inhibition influences reaction time and response selection. Journal of Experimental Psychology: General, 131, 255-269.

Klauer, K. C. (1998). Affective priming. European Review of Social Psychology, 8, 67-103

Klauer, K. C., \& Greenwald, A. G. (2000). Measurement error in subliminal perception experiments: Simulation analyses of two regression methods-Comment on Miller (2000). Journal of Experimental Psychology: Human Perception \& Performance, 26, 1506-1508. 
KLINGER, M. R. (2001). The role of attention and awareness in the false recognition effect. American Journal of Psychology, 114, 93-114.

KLinger, M. R., Burton, P. C., \& PitTs, G. S. (2000). Mechanisms of unconscious priming: I. Response competition, not spreading activation. Journal of Experimental Psychology: Learning, Memory, \& Cognition, 26, 441-455.

KLINGER, M. R., \& GREENWALD, A. G. (1995). Unconscious priming of association judgments. Journal of Experimental Psychology: Learning, Memory, \& Cognition, 21, 569-581.

KLOTZ, W., \& NeUMANN, O. (1999). Motor activation without conscious discrimination in metacontrast masking. Journal of Experimental Psychology: Human Perception \& Performance, 25, 976-992.

KLOTZ, W., \& WoLFF, P. (1995). The effect of a masked stimulus on the response to the masking stimulus. Psychological Research, 58, 92-101.

KoRnBLuM, S. (1992). Dimensional overlap and dimensional relevance in stimulus-response and stimulus-stimulus compatibility. In G. E. Stelmach \& J. Requin (Eds.), Tutorials in motor behavior II (pp. 743777). Amsterdam: North-Holland.

Kornblum, S., HasbroucQ, T., \& Osman, A. (1990). Dimensional overlap: Cognitive basis for stimulus-response compatibility: A model and taxonomy. Psychological Review, 97, 253-270.

Kornblum, S., \& LeE, J. W. (1995). Stimulus-response compatibility with relevant and irrelevant stimulus attributes that do and do not overlap with the response: A model and taxonomy. Journal of Experimental Psychology: Human Perception \& Performance, 21, 855-875.

KouIder, S., \& Dupoux, E. (2004). Partial awareness creates the "illusion" of subliminal semantic priming. Psychological Science, 15, 75-81.

Kunimoto, C., Miller, J., \& Pashler, H. (2001). Confidence and accuracy of near-threshold discrimination responses. Consciousness \& Cognition, 10, 294-340.

LEUTHOLD, H., \& KoPP, B. (1998). Mechanisms of priming by masked stimuli: Inferences from event-related brain potentials. Psychological Science, 9, 263-269.

LUPKER, S. J. (1986). Conscious identification: Where do you draw the line? Behavioral \& Brain Sciences, 9, 37-38.

Macmillan, N. A. (1986). The psychophysics of subliminal perception. Behavioral \& Brain Sciences, 9, 38-39.

MARCEL, A. J. (1980). Conscious and preconscious recognition of polysemous words: Locating the selective effects of prior verbal context. In R. S. Nickerson (Ed.), Attention and performance VIII (pp. 435-457). Hillsdale, NJ: Erlbaum.

MarCel, A. J. (1983a). Conscious and unconscious perception: Experiments on visual masking and word recognition. Cognitive Psychology, 15, 197-237.

MARCEL, A. J. (1983b). Conscious and unconscious perception: An approach to the relations between phenomenal experience and perceptual processes. Cognitive Psychology, 15, 238-300.

Merikle, P. M., \& Cheesman, J. (1986). Consciousness is a "subjective" state. Behavioral \& Brain Sciences, 9, 42.

Merikle, P. M., \& Cheesman, J. (1987). Current status of research on subliminal perception. Advances in Consumer Research, 14, 298-302.

Merikle, P. M., \& Joordens, S. (1997). Parallels between perception without attention and perception without awareness. Consciousness \& Cognition, 6, 219-236.

MERIKLe, P. M., Joordens, S., \& Stolz, J. A. (1995). Measuring the relative magnitude of unconscious influences. Consciousness \& Cognition, 4, 422-439.

MERIKLE, P. M., \& REINGold, E. M. (1990). Recognition and lexical decision without detection: Unconscious perception? Journal of Experimental Psychology: Human Perception \& Performance, 16, 574-583.

Merikle, P. M., \& ReINGOLD, E. M. (1998). On demonstrating unconscious perception: Comment on Draine and Greenwald (1998). Journal of Experimental Psychology: General, 127, 304-310.

Merikle, P. M., SmileK, D., \& Eastwood, J. D. (2001). Perception without awareness: Perspectives from cognitive psychology. Cognition, 79, 115-134.

Michaels, C. F., \& Turvey, M. T. (1979). Central sources of visual masking: Indexing structures supporting seeing at a single, brief glance. Psychological Research, 41, 1-61.

MiLLER, J. (2000). Measurement error in subliminal perception experiments: Simulation analyses of two regression methods. Journal of Ex- perimental Psychology: Human Perception \& Performance, 26, 14611477.

Miller, J., \& NAvon, D. (2002). Global precedence and response activation: Evidence from LRPs. Quarterly Journal of Experimental Psychology, 55A, 289-310.

NACCACHE, L., \& DEHAENE, S. (2001). Unconscious semantic priming extends to novel unseen stimuli. Cognition, 80, 223-237.

NeELY, J. H. (1977). Semantic priming and retrieval from lexical memory: Roles of inhibitionless spreading activation and limited-capacity attention. Journal of Experimental Psychology: General, 106, 226254.

Neumann, O., \& Klotz, W. (1994). Motor responses to nonreportable, masked stimuli: Where is the limit of direct parameter specification? In C. Umiltà \& M. Moscovitch (Eds.), Attention and performance XV: Conscious and nonconscious information processing (pp. 123-150). Cambridge, MA: MIT Press.

PAAP, K. R. (1986). The pilfering of awareness and guilt by association. Behavioral \& Brain Sciences, 9, 45-46.

Perruchet, P., \& Vinter, A. (2002). The self-organizing consciousness. Behavioral \& Brain Science, 25, 297-330.

Reingold, E. M., \& Merikle, P. M. (1988). Using direct and indirect measures to study perception without awareness. Perception \& Psychophysics, 44, 563-575.

SCHLAGHECKEN, F., \& EIMER, M. (1997). The influence of subliminally presented primes on response preparation. Sprache und Kognition, 16, 166-175.

Schlaghecken, F., \& Eimer, M. (2002). Motor activation with and without inhibition: Evidence for a threshold mechanism in motor control. Perception \& Psychophysics, 64, 148-162.

SEARLE, J. R. (1983). Intentionality: An essay in the philosophy of mind. Cambridge: Cambridge University Press.

SEARLE, J. R. (1990). Consciousness, explanatory inversion, and cognitive science. Behavioral \& Brain Sciences, 13, 585-642.

SEARLE, J. R. (1992). The rediscovery of the mind. Cambridge, MA: MIT Press.

Segui, J., \& Beauvillain, C. (1987). Why limit the availability of a primeword in the study of automatic contextual facilitation? Behavioral \& Brain Sciences, 10, 766-767.

SNODGRAss, M. (2002). Disambiguating conscious and unconscious influences: Do exclusion paradigms demonstrate unconscious perception? American Journal of Psychology, 115, 545-579.

Snodgrass, M., Bernat, E., \& Shevrin, H. (2004). Unconscious perception: A model-based approach to method and evidence. Perception \& Psychophysics, 66, 846-867.

SNODGRASS, M., \& S TEVRIN, H. (2002). Unconscious inhibition and facilitation at the objective threshold: Replicable and qualitatively different unconscious perceptual effects. Manuscript submitted for publication.

SnOdgrass, M., Shevrin, H., \& KopKa, M. (1993). The mediation of intentional judgments by unconscious perceptions: The influences of task strategy, task preference, word meaning, and motivation. Consciousness \& Cognition, 2, 169-193.

SwETS, J. A. (ED.) (1996). Signal detection theory and ROC analysis in psychology and diagnostics: Collected papers. Mahwah, NJ: Erlbaum.

TuRVEY, M. T. (1973). On peripheral and central processes in vision: Inferences from an information-processing analysis of masking with patterned stimuli. Psychological Review, 80, 1-52.

Tzelgov, J., Porat, Z., \& HeniK, A. (1997). Automaticity and consciousness: Is perceiving the word necessary for reading it? American Journal of Psychology, 110, 429-448.

UTTAL, W. R. (1998). Toward a new behaviorism: The case against perceptual reductionism. Mahwah, NJ: Erlbaum.

UtTAL, W. R. (2000). The war between mentalism and behaviorism: On the accessibility of mental processes. Mahwah, NJ: Erlbaum.

UtTaL, W. R. (2001). The new phrenology: The limits of localizing cognitive processes in the brain. Cambridge, MA: MIT Press.

Van Selst, M., \& Merikle, P. (1993). Perception below the objective threshold? Consciousness \& Cognition, 2, 194-203.

VISSER, T. W. A., \& MERIKLE, P. M. (1999). Conscious and unconscious cognition: The effect of motivation. Consciousness \& Cognition, $\mathbf{8}$, 94-113. 
Vorberg, D., Mattler, U., Heinecke, A., Schmidt, T., \& SchwarzBACH, J. (2003). Different time courses for visual perception and action priming. Proceedings of the National Academy of Sciences, $\mathbf{1 0 0}_{2}$ 6275-6280.

Whittlesea, B. W. A., \& JACOBY, L. L. (1990). Interaction of prime repetition with visual degradation: Is priming a retrieval phenomenon? Journal of Memory \& Language, 29, 546-565.

Whittlesea, B. W. A., \& Price, J. R. (2001). Implicit/explicit memory versus analytic/nonanalytic processing: Rethinking the mere exposure effect. Memory \& Cognition, 29, 234-246.

ZaJonc, R. B. (1980). Feeling and thinking: Preferences need no inferences. American Psychologist, 35, 151-175.

\section{NOTES}

1. In the present paper, we are concerned exclusively with situations in which the target and the mask spatially overlap, thus disregarding metacontrast, in which the contours of the backward mask are adjacent to those of the target.

2. Strictly speaking, a classic visual subliminal effect not attributable to masking could be observed only by manipulating either the duration or the intensity (or both) of a stimulus presented between completely dark pre- and postexposure fields. Peripheral masking by light would contribute to the effect as soon as the preexposure field or the postexposure field has nonzero luminances.

3. This statement is meaningful only in the context of theories that attribute at least part of the "priming" effect to some form of a spreading activation process elicited by the prime and taking place in lexico- semantic memory. In a retrieval theory such as that of Whittlesea and Jacoby (1990), the notion of "priming" effect is a misnomer.

4. Both Greenwald et al.'s (1995, p. 39) interpretation of negative $d$ ' and the correction for measurement error (see Klauer \& Greenwald, 2000) rest on the assumption that negative values of $d^{\prime}$ are due to measurement error. However, it is unlikely that values of $d^{\prime}$ as large as -1.0 represent measurement error. Otherwise, there is no reason not to consider positive values of $d^{\prime}$ as large as +1.0 as reflecting measurement error as well. At least the largest values of the negative $d^{\prime}$ should represent incorrect discriminative responding (see Haase \& Fisk, 2004). Thus, it is far from clear that the pattern of results observed in Figure 4 and in the right panel of Figure 6 in Snodgrass et al. (2004) could be interpreted in the same way as one can interpret the nonmonotonic relation between priming and SOA length in Dagenbach, Carr, and Wilhelmsen's (1989) study.

5. It must be realized that for the subset of participants showing the correct threshold ordering in Experiment 1 of Dagenbach et al. (1989, Table 2), the detection SOA was only 2.4 and $6.1 \mathrm{msec}$ shorter than the corresponding identification thresholds.

6. For example, detecting the presence of a stimulus sandwiched between a forward and a backward mask, which is itself immediately followed by a visible target stimulus, as in Dehaene, Naccache, et al.'s (1998) experiment, might well be as difficult or even more difficult than resolving confusable stimulus cues of uncertain origin (i.e., mask features vs. prime features) through a retroactive clarification process based on the target.

(Manuscript received February 18, 2003; revision accepted for publication October 10, 2003.) 